\title{
Peritoneal carcinomatosis of colorectal origin: is it really an end-stage disease?
}

\author{
E. Chouillard $\cdot$ V. Greco $\cdot$ N. Tsiminikakis
}

Received: 15 July 2013/Accepted: 18 August 2013/Published online: 6 September 2013

(C) Springer-Verlag Italia 2013

Peritoneal carcinomatosis (PC) is no longer considered as a systemic disease. There is mounting evidence for a local spread theory [1]. Peritoneal tumor implantation occurs due to multiple mechanisms including serosal invasion, leakage of malignant cells through the lymphatics, or as a result of imprudent dissection [2].

The exact extent of the PC can be determined precisely only during surgery. The peritoneal cancer index (PCI, Washington Cancer Institute) is usually used to quantify PC. This explains why the estimation of the extent of PC was sub-optimal in historical series where patients were treated systematically without formal staging [3].

In the most recent revision of the TNM staging system [4], metastatic colorectal cancer (CRC) at initial diagnosis is sub-classified into stage IVA or IVB disease according to the number or site of metastases. In this system, PC is subclassified into stage IVB, whereas other metastases to a sole organ such as liver or lung are sub-classified into stage IVA, which is considered to indicate better survival. The new TNM classification system was proposed and validated before publication by the American Joint Committee on Cancer (AJCC) Hindgut Taskforce based on a large population-based study, surveillance, epidemiology, and end results (SEER) of patients with CRC treated between 1994 and 2005 in the USA [5, 6].

The major historical series (i.e., before the era of newer chemotherapy, cytoreductive surgery [CRS], and heated

On behalf of the Intercontinental Society of Natural Orifice, Endoscopic, and Laparoscopic Surgery ( $i$ NOELS), France.

E. Chouillard $(\bowtie) \cdot$ V. Greco $\cdot$ N. Tsiminikakis Oncological Surgery Unit, Department of Surgery, Paris/Poissy Medical Center (PPMC), 10 rue du Champ Gaillard, 78300 Poissy, France

e-mail: chouillard@yahoo.com intraperitoneal chemotherapy, [HIPEC]) suggested a poor prognosis with a median survival around 6 months and absolutely no long-term survivors [6-8].

However, for almost a decade now, the prognosis of patients with PC of colorectal origin has been improving. This is mainly due to two factors, the use of oxaliplatinbased chemotherapy [9] and the combination of CRS with HIPEC as a possible treatment modality [10].

These findings raise the question of whether sub-classification into stage IVB is still appropriate and clinically relevant.

Ishida et al. [11] conducted a retrospective study in order to investigate the overall survival in metastatic CRC patients based on the sites of metastasis in the era of modern chemotherapy. The authors found that patients with isolated PC had a median survival of 36.6 months, as compared to a median survival of 32.5 months $(p=0.48)$ for patients in the IVA group. These figures were significantly higher than those of patients with distant metastases with or without PC $[14.7$ months $(p=0.07)$ and 12.9 months $(p<0.01)$, respectively]. The authors recommend including patients with isolated PC in the IVA group rather than those in the IVB group.

Only about a third of all patients with PC would be suitable for an aggressive, multimodal therapy, combining CRS with HIPEC and systemic chemotherapy. In order to improve the prognosis, complete resection of the entire macroscopically visible tumor mass is mandatory. Remaining microscopic tumor cells should be eradicated immediately after resection with HIPEC. With such an approach, median survival has been reported to reach more than 30 months, with 3- or 5-year survival rates of more than $30 \%$, in some series [12]. Patient selection is, however, crucial. A positron emission tomography (PET) scan is a valuable tool for selecting patients with isolated PC 
[13]. It is effective in detecting PC and has the potential to improve clinical diagnosis when coupled with an understanding of the pathways of flow for ascitic fluid and peritoneal seeding.

The efficacy of CRS-HIPEC for patients with PC is to be weighed against its inherent high morbidity and mortality rates. Mortality rates up to $19 \%$ and morbidity rates up to $55 \%$ have been, respectively, reported with some CRS-HIPEC regimens [14]. However, the mortality rate in centers where more than 100 patients have already been treated is less than $3 \%$ [15]. Median survival following complete resection (R0) of all microscopic diseases ranged from 18 to 39 months [16]. In the same R0 setting, 5-year survival ranged from 20 to $54 \%$ [16]. On the other hand, when more than 5-mm residual disease was left behind, median survival oscillated between 5 and 12 months, with no 5-year survivors, figures mimicking those reported in historical series [16]. Multidisciplinary tumor board agreement is needed to pursue this aggressive combined treatment strategy.

The available systematic studies of postoperative quality of life show-depending on the extent of the surgery and the rate of peri- and postoperative complications-a deterioration in quality of life in the first few weeks following surgery. However, most patients achieve at least the same level of quality of life as before the operation during the few months following surgery [16].

In the absence of prospective studies, the analysis of the French register shows that adjuvant systemic chemotherapy correlates with a better prognosis for the patient, with a median survival of 34 months and a 5-year survival of over $30 \%$ [12].

Even if long-term survival has been achieved with aggressive treatment of patients with PC, patients with this disease have a dismal prognosis, with only less than $30 \%$ being candidates for possible long-term survival. Our team believes that adjuvant HIPEC could theoretically reduce the risk of $\mathrm{PC}$ in selected patients undergoing surgery with curative intent for CRC. In 2005, we proposed a pilot study to evaluate the feasibility, safety, and short-term outcome of laparoscopic adjuvant HIPEC in selected patients after complete resection of locally advanced colorectal or gastric cancer. The preliminary results of this study have already been published [17].

Mid-term results are yet to be published. However, the overall follow-up period of the patients who survived more than 2 years was 30.5 months (range 24-49 months). Only $12 \%$ of these high-risk patients developed PC, while the theoretical risk could be up to $55 \%[18,19]$.

In summary, although the pathophysiology of PC is different from that of liver metastases, both diseases have roughly comparable outcomes. In selected cases, long-term survival could be achieved utilizing combined, aggressive medico-surgical regimens. Moreover, in patients at high risk of developing PC, adjuvant HIPEC could be of some interest in the future. Further large-scale evaluation is recommended.

\section{Conflict of interest None.}

\section{References}

1. Confuorto G, Giuliano ME, Grimaldi A, Viviano C (2007) Peritoneal carcinomatosis from colorectal cancer: HIPEC? Surg Oncol 16:S149-S152

2. Witkamp AJ, de Bree E, Kaag MM et al (2001) Extensive cytoreductive surgery followed by intra-operative hyperthermic intraperitoneal chemotherapy with mitomycin-C in patients with peritoneal carcinomatosis of colorectal origin. Eur $\mathrm{J}$ Cancer 37:979-984

3. Sadeghi B, Arvieux C, Glehen O et al (2000) Peritoneal carcinomatosis from non-gynecologic malignancies: results of the EVOCAPE 1 multicentric prospective study. Cancer 88:358-363

4. Sobin LH, Gospodarowicz MK, Wittekind C (2009) TNM classification of malignant tumors, 7th edn. Wiley, London

5. Gunderson LL, Jessup JM, Sargent DJ, Greene FL, Stewart AK (2010) Revised TN categorization for colon cancer based on national survival outcomes data. J Clin Oncol 28:264-271

6. Gunderson LL, Jessup JM, Sargent DJ, Greene FL, Stewart A (2010) Revised tumor and node categorization for rectal cancer based on surveillance, epidemiology, and end results and rectal pooled analysis outcomes. J Clin Oncol 28:256-263

7. Chu DZ, Lang NP, Thompson C, Osteen PK, Westbrook KC (1989) Peritoneal carcinomatosis in nongynecologic malignancy. A prospective study of prognostic factors. Cancer 63:364-367

8. Jayne DG, Fook S, Loi C, Seow-Choen F (2002) Peritoneal carcinomatosis from colorectal cancer. Br J Surg 89:1545-1550

9. Lee DH, Oh SY, Lee YR et al (2011) A phase II study of modified FOLFOX4 for colorectal cancer patients with peritoneal carcinomatosis. Cancer Res Treat 43:225-230

10. Verwaal VJ, van Ruth S, de Bree E et al (2003) Randomized trial of cytoreduction and hyperthermic intraperitoneal chemotherapy versus systemic chemotherapy and palliative surgery in patients with peritoneal carcinomatosis of colorectal cancer. J Clin Oncol 21:3737-3743

11. Ishida H, Kumamoto K, Ishibashi K et al (2013) Should isolated peritoneal carcinomatosis from colorectal cancer be sub-classified into stage IVB in era of modern chemotherapy? Tech Coloproctol. doi:10.1007/s10151-012-0972-9

12. Macri A, Saladino E, Bartolo V et al (2010) Peritoneal carcinomatosis of colorectal origin? World J Gastrointest Oncol 2:98-101

13. Bamba Y, Itabashi M, Kameoka S (2012) Clinical use of PET/CT in peritoneal carcinomatosis from colorectal cancer. Hepatogastroenterology 59:1408-1411

14. Chua TC, Yan TD, Saxena A et al (2009) Should treatment of peritoneal carcinomatosis by cytoreductive surgery and hyperthermic intraperitoneal chemotherapy still be regarded as a highly morbid procedure? A systematic review of morbidity and mortality. Ann Surg 249:900-907

15. Koppe MJ, Boerman OC, Oyen WJ, Bleichrodt RP (2006) Peritoneal carcinomatosis of colorectal origin: incidence and current treatment strategies. Ann Surg 243:212-222

16. Glockzin G, Schlitt HJ, Piso P (2009) Peritoneal carcinomatosis: patients selection, perioperative complications and quality of life related to cytoreductive surgery and hyperthermic intraperitoneal chemotherapy. World J Surg Oncol 7:5 
17. Chouillard E, Ata T, De Jonghe B et al (2009) Staged laparoscopic adjuvant intraperitoneal chemohyperthermia after complete resection for locally advanced colorectal or gastric cancer: a preliminary experience. Surg Endosc 23:363-369

18. Elias D, Glehen O, Pocard M et al (2010) A comparative study of complete surgery plus intraperitoneal chemotherapy to treat peritoneal dissemination from colon, rectum, small bowel and nonpseudomyxoma appendix. Ann Surg 251:896-901

19. Elias D, Goéré D, Di Pietrantonio D et al (2008) Results of systemic second- look surgery in patients at high risk of developing colorectal peritoneal carcinomatosis. Ann Surg 247:445-450 